\title{
ВЛИЯНИЕ КОМПЛЕКСА МИКРОУДОБРЕНИЙ НА ПРОДУКТИВНОСТЬ КЛЕВЕРА ЛУГОВОГО В УСЛОВИЯХ КОСТРОМСКОЙ ОБЛАСТИ
}

\section{Клевер, Аквамикс, предпосевная обработка семян, некорневые подкормки, урожсайность, качество семян}

\section{Clover, Aquamix,} pre-sowing seed treatment, topdressing, productivity, seed quality

\section{Г.В. Попова}

научный сотрудник отдела инновационных разработок в растениеводстве ФГБНУ «Костромской научно-исследовательский институт сельского хозяйства», с. Минское

Повышение урожайности сельскохозяйственных культур и качества продукции остаётся одной из важнейших задач агропромышленного комплекса России. Для её достижения используются различные технологии выращивания, совершенствуются отдельные элементы технологий, применяются новые агроприёмы. Одним из таких приёмов является использование комплекса микроэлементов при выращивании клевера лугового. Клевер является одной из основных культур, возделываемых на кормовые цели в Костромской области, по питательной ценности превосходящий многие полевые культуры [1].

Нашими исследованиями доказано, что целенаправленные и научно обоснованные приёмы применения комплекса водорастворимых удобрений могут обеспечить устойчивое и стабильное развитие кормопроизводства при незначительной зависимости от погодных условий и других неблагоприятных факторах роста [3]. Одним из таких комплексов, на наш взгляд, является препарат «Аквамикс» (производитель Буйский химический завод). Это сбалансированный водорастворимый комплекс микроэлементов, содержащий пять основных веществ в форме хелатов - Mo, B, Co, Cu и Zn, a также Fe и Mn в легкодоступной для растений форме [4].

Выпускают две марки удобрения:

- Аквамикс-Т: марка предназначена для предпосевной обработки семян. Повышает энергию прорастания и всхожесть семян, усиливает устойчивость растений к неблагоприятным факторам роста (применяется в дозе 40 г на гектарную норму семян при расходе рабочей жидкости 10 л/т семян);

- Аквамикс-ТВ: марка предназначена для некорневых подкормок в период вегетации. Способствует повышению урожайности 
бобовых на 10-15\%, усиливая процессы биологической азотфиксации (применяется в дозе 150 г/га, расход рабочего раствора 250-300 л/га). Использование Аквамикс-ТВ особенно эффективно на семеноводческих посевах, так как улучшает процессы опыления и оплодотворения, тем самым повышая урожайность и качество семян [4].

В наших исследованиях изучалось влияние предпосевной обработки семян и некорневой подкормки во время вегетации водорастворимым удобрением «Аквамикс» на урожайность зелёной массы и семян клевера лугового сорта Солигаличский местный (оригинатор - ФГБНУ «Костромской HИИСХ») в условиях Костромской области.

Клевер луговой сорта Солигаличский местный относится к группе позднеспелых одноукосных клеверов. Характеризуется медленным развитием в первый год жизни, к зиме образует лишь розетку из укороченных стеблей. Зимостойкий. Весной отрастает медленно, укосную массу формирует в июле-начале августа [5]. Урожайность зелёной массы выше средней и может достигать 60-80 т/га. Урожайность семян нестабильная, в среднем 1-3 ц/га. Семена более мелкие, с меньшей массой 1000 семян, по сравнению с другими сортами клевера лугового [6].

\section{Методика}

Исследования проводились в 2017-2018 годах. Почвы участка - дерново-подзолистый легкий суглинок со средним показателем гумуса, повышенным содержанием фосфора и средним содержанием калия, кислотность нейтральная, близкая к щелочной. Предпосевная обработка почвы состояла из дискования по зяблевой вспашке с последующей культивацией в 2 следа со сменой угла атаки и предпосевного прикатывания кольчатыми катками по ходу сева. С учётом посевной годности норма высева составила 15 кг/га, посев проведён 15 мая рядовым способом беспокровно. Половина предназначенных для посева семян была обработана, вторая половина посеяна без предпосевной подготовки. Обработка проводилась за день до посева путём опрыскивания семян свежеприготовленным раствором Аквамикс-Т, с дальнейшим подсушиванием их до сыпучего состояния.

Сложные минеральные удобрения $\left(\mathrm{N}_{26} \mathrm{P}_{38} \mathrm{~K}_{38}\right)$ внесены общим фоном под культивацию, а также в конце вегетационного периода в виде подкормки $\left(\mathrm{P}_{45} \mathrm{~K}_{70}\right)$. Учёты и наблюдения выполнены согласно «Методике полевого опыта» Б.А. Доспехова [7], «Методическим указаниям по проведению полевых опытов с кормовыми культурами» [8] и «Методике государственного сортоиспытания сельскохозяйственных культур» [9]. Применяемая в опыте агротехника общепринятая для Костромской области.

Схема исследований приведена в таблице 1.

\section{Результаты исследований}

Исследования 2017 года показали, что обработка семян клевера комплексом Аквамикс-Т ока-

Таблица 1 - Схема исследований

\begin{tabular}{|c|c|c|}
\hline \multirow{2}{*}{ № варианта } & \multicolumn{2}{|r|}{ Год жизни клевера } \\
\hline & $1-и ̆$ & $2-\breve{~}$ \\
\hline 1 & \multirow{4}{*}{ без удобрений } & Контроль \\
\hline 2 & & Аквамикс-ТВ в фазу отрастания \\
\hline 3 & & Аквамикс-ТВ, фаза стеблевания \\
\hline 4 & & Аквамикс-ТВ, фаза отрастания + фаза стеблевания \\
\hline 5 & \multirow{4}{*}{ Аквамикс-Т } & Контроль \\
\hline 6 & & Аквамикс-ТВ, фаза отрастания \\
\hline 7 & & Аквамикс-ТВ, фаза стеблевания \\
\hline 8 & & Аквамикс-ТВ, фаза отрастания + фаза стеблевания \\
\hline
\end{tabular}

зала положительное влияние на рост и развитие растений 1-го года жизни. Они были более жизнеспособными и устойчивыми к неблагоприятным факторам роста (погодные условия, обработка пестицидами), чем растения без предпосевной обработки. За летний период в контрольном варианте выпало 8-55\%, а в опытном варианте всего до $6 \%$ растений. 
Погодные условия зимнего периода 20172018 гг. в целом были благоприятны для перезимовки клевера 1-го года жизни. Этому способствовали большая высота снежного покрова (до 60 см), а также раннее и дружное оттаивание снега весной. Запас продуктивной влаги в почве был достаточный (150-155 мм), и в середине апреля началось массовое отрастание клевера 2-го года жизни. Согласно исследованиям, зимостойкость растений в вариантах с обработкой семян Аквамикс-Т в среднем составила 59\%, что на $18 \%$ выше, чем в вариантах без обработки семян.

Фенологические наблюдения показали, что предпосевная обработка семян оказывала положительное влияние в течение всего вегетационного периода и в последующие годы жизни растений. Так, в опытных вариантах среднее количество междоузлий на конец фазы стеблевания составило 9,4 шт., средняя длина стеблей -
150 см, а в контрольных вариантах они были меньше на 0,3 шт. и 15 см соответственно. В опытных вариантах засорённость посевов сорняками была существенно меньше, чем в контрольных вариантах.

Исследования показали, что созревание семян в вариантах с Аквамикс-Т прошло в более сжатые сроки, что очень важно при неустойчивых погодных условиях этого периода в Костромской области. Наблюдения, проведённые 10 августа, свидетельствуют, что в вариантах с Аквамикс-Т количество побуревших семенных головок было на 19\% выше, чем в контрольных вариантах, и составило в среднем 75\%.

Согласно схеме исследований, в фазы отрастания и стеблевания были проведены некорневые подкормки растений раствором удобрения Аквамикс-ТВ. В фазу конец бутонизации - начало цветения были взяты образцы для определения

Таблица 2 - Урожайность зелёной массы, семян и анализ качества полученных семян клевера

\begin{tabular}{|c|c|c|c|c|c|c|c|c|}
\hline \multirow[b]{2}{*}{ Вариант } & \multirow[b]{2}{*}{ Фон } & \multicolumn{4}{|c|}{ Урожайность } & \multirow{2}{*}{$\begin{array}{c}\text { Масса } 1000 \\
\text { семян, г }\end{array}$} & \multirow{2}{*}{$\begin{array}{c}\text { Энергия } \\
\text { прораста- } \\
\text { ния, \% }\end{array}$} & \multirow{2}{*}{$\begin{array}{c}\text { Всхо- } \\
\text { жесть, \% }\end{array}$} \\
\hline & & $\begin{array}{c}\text { зелёной } \\
\text { массы, т/га }\end{array}$ & \pm к контролю & семян, ц/га & \pm к контролю & & & \\
\hline 1 & \multirow{5}{*}{ 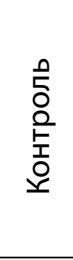 } & 33,7 & - & 1,05 & - & 1,55 & 50 & 68 \\
\hline 2 & & 43,7 & $+10,0$ & 1,41 & $+0,36$ & 1,60 & 72 & 83 \\
\hline 3 & & 42,9 & $+9,2$ & 1,50 & $+0,45$ & 1,60 & 56 & 73 \\
\hline 4 & & 49,6 & $+15,9$ & 1,77 & $+0,72$ & 1,66 & 79 & 85 \\
\hline $\mathrm{HCP}_{05}$ & & 15,5 & - & 0,18 & - & - & - & - \\
\hline 5 & \multirow{5}{*}{ 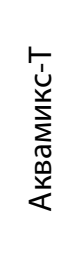 } & 37,8 & - & 1,24 & - & 1,60 & 56 & 76 \\
\hline 6 & & 50,8 & $+13,0$ & 1,30 & $+0,06$ & 1,63 & 78 & 81 \\
\hline 7 & & 41,2 & $+3,4$ & 1,38 & $+0,14$ & 1,63 & 61 & 78 \\
\hline 8 & & 52,4 & $+14,6$ & 1,59 & $+0,35$ & 1,68 & 82 & 87 \\
\hline $\mathrm{HCP}_{05}$ & & 10,7 & - & 0,16 & - & - & - & - \\
\hline
\end{tabular}

урожайности зелёной массы, а по достижению фазы побурения головок на уровне 85-90\% и после десикации посевов препаратом «РеглонСупер» - на урожайность семян. После уборки семян была проведена их проверка на посевную годность согласно методике [12, с. 175-176].

Данные по урожайности зелёной массы, семян и анализу качества полученных семян представлены в таблице 2.

В вариантах 1-4, по контрольному фону, урожайность зелёной массы составила 33,7-49,6 т/га. Достоверное увеличение урожайности получено только в варианте № 4, при двойной подкормке
Аквамикс-ТВ в фазы отрастания и стеблевания. Увеличение урожайности составило 15,9 т/га. В вариантах 5-8, с предпосевной обработкой семян, урожайность зелёной массы составила 37,852,4 т/га.

Достоверное увеличение получено в двух вариантах (6 и 8) при применении Аквамикс-ТВ в фазу отрастания и совместного его применения в фазы отрастания и стеблевания. В этих вариантах урожайность зелёной массы была больше на 13,0 и 14,6 т/га по сравнению с контролем. В вариантах 3 и 7, с подкормкой Аквамикс-ТВ в фазу стеблевания, увеличение урожайности было 
недостоверным по обоим фонам и составило 9,2 и 3,4 т/га соответственно.

Урожайность семян в вариантах 1-4 составила 105-177 кг/га. Достоверное увеличение урожайности на 36-72 кг/га наблюдалось по всем вариантам фона, но наибольшей (72 кг/га) она была в варианте 4 при обработке Аквамикс-ТВ в фазы отрастание + стеблевание.

В вариантах 5-8 урожайность семян составила 124-159 кг/га. Достоверное увеличение урожайности на 35 кг/га получено лишь в варианте 8 , при двойной подкормке во время вегетации. Однократное применение Аквамикс-ТВ в вариантах 6 и 7 не повлияло на существенное увеличение урожайности семян, прибавка составила только 6 и 14 кг/га соответственно.

В ходе исследований был проведён анализ семян на посевную годность. Масса 1000 семян в вариантах 1-4 составила 1,55-1,66 г, энергия про- растания - 50-79\%, всхожесть семян - 68-85\%. По всем показателям по контрольному фону выделились варианты с применением Аквамикс-ТВ в фазы отрастания и двойным применением в фазы отрастание + стеблевание. По сравнению с контролем масса 1000 семян в этих вариантах (2 и 4) была больше на 0,05 и 0,11 г, энергия прорастания - выше на 22 и 29\%, а всхожесть семян больше на 15 и 17\% соответственно. Применение Аквамикс-ТВ в фазу стеблевания не повлияло на значительное улучшение показателей посевной годности семян.

В вариантах 5-8 масса 1000 семян составила $1,60-1,68$ г, энергия прорастания - 56-82\%, всхожесть семян - 76-87\%. Лучшие по качеству семена также получены в вариантах с применением Аквамикс-ТВ в фазы отрастания и двойного применения в фазы отрастание + стеблевание. Масса 1000 семян в вариантах 6 и 8 по сравнению с

Таблица 3 - Экономическая эффективность применения комплекса «Аквамикс» при выращивании клевера лугового

\begin{tabular}{|c|c|c|c|c|c|c|}
\hline \multirow[b]{2}{*}{ Вариант } & \multirow[b]{2}{*}{$\begin{array}{c}\text { Затраты всего, } \\
\text { руб./га }\end{array}$} & \multirow[b]{2}{*}{ 土 к контролю, \% } & \multicolumn{4}{|c|}{ Себестоимость } \\
\hline & & & $\begin{array}{c}\text { зелёная мас- } \\
\text { са, руб./т }\end{array}$ & $\underset{\%}{ \pm \text { к контролю, }}$ & семена, руб./ц & $\begin{array}{c} \pm \text { к контролю, } \\
\%\end{array}$ \\
\hline Контроль & 10600 & - & 315 & - & 10095 & - \\
\hline 4 & 13000 & +22 & 262 & -17 & 7345 & -27 \\
\hline 8 & 13600 & +28 & 260 & -18 & 8553 & -15 \\
\hline
\end{tabular}

контролем была больше на 0,03 и 0,08 г, энергия прорастания - выше на 22 и 26\%, всхожесть семян - на 5 и $11 \%$ соответственно.

Последействие предпосевной обработки семян комплексом Аквамикс-Т, без применения дополнительных подкормок, обеспечило прибавку урожайности зелёной массы клевера на 4,1 т/га, а семян - на 20 кг/га, по сравнению с контрольным вариантом.

По результатам исследований были выделены варианты с лучшими показателями (варианты № 4 и 8) и по ним рассчитана экономическая эффективность применения комплекса «Аквамикс» (табл. 3).

Расчёт экономической эффективности показал, что несмотря на увеличение затрат в расчёте на 1 гектар на 22 и 28\% по сравнению с контролем, себестоимость 1 т зелёной массы снижается на 17 и 18\%, а себестоимость производства 1 ц семян - на 27 и 15\% соответственно.
Из представленных расчётов очевидны преимущества инновационного приёма (технологии) - использования водорастворимого комплекса «Аквамикс» при выращивании зелёной массы и семян клевера лугового в Костромской области.

\section{Выводы}

1. Предпосевная обработка семян комплексом Аквамикс-Т оказала благоприятное влияние на растения 1-го года жизни. Они отличались лучшей устойчивостью и конкурентоспособностью к факторам естественного отбора по сравнению с контролем. Зимостойкость растений в вариантах с Аквамикс-Т была выше на 18\%, чем в контрольных вариантах и составила $59 \%$.

2. Наибольшая урожайность зелёной массы (49-52 т/га) получена при двукратной подкормке клевера комплексом Аквамикс-ТВ в фазы отрастание + стеблевание. Самое высокое достовер- 
ное увеличение (+16 т/га) получено по фону с обработкой семян Аквамикс-Т.

3. Более высокая урожайность семян (160170 кг/га) также получена при двукратном применении Аквамикс-ТВ на клевере 2-го года жизни. Наибольшая достоверная прибавка (+70 кг/ га) была получена по контрольному фону. Клевер без предпосевной обработки семян более отзывчив на подкормки микроудобрениями в течение вегетации при количественном формировании урожая семян.

4. Качество семян было выше в вариантах с применением Аквамикс-ТВ в фазу отрастания и совместном его применении в фазы отрастание + стеблевание. Получение дополнительного питания в течение вегетации положительно сказалось на посевных качествах семян.
5. Последействие предпосевной обработки семян комплексом Аквамикс-Т обеспечило прибавку урожайности зелёной массы (на 4,1 т/га) и семян (на 20 кг/га).

6. Применение комплекса «Аквамикс» в фазы отрастание + стеблевание существенно снижает себестоимость продукции.

Таким образом, на основании наших исследований можно сделать вывод, что клевер наиболее отзывчив на опрыскивание раствором микроэлементов в фазу отрастания, в период интенсивного наращивания зелёной массы после перезимовки. Последующие обработки комплексом АквамиксТВ способствуют дальнейшему повышению урожайности зелёной массы и семян клевера, а также положительно влияют на посевные качества полученных семян.

\section{תumepamypa}

1. Мухина, Н.А. Клевер красный [Текст] / Н.А. Мухина. - Колос, 1971. - 85 с.

2. Солоничкин, В.Н. Оптимизация питания сельскохозяйственных культур на основе применения некорневых подкормок специальными удобрениями [Текст]: пособие для агрономов / В.Н. Солоничкин. Буй, 2006. -24 с.

3. Попова, Г.В. Использование сортового разнообразия клевера лугового для создания сырьевого конвейера в условиях Костромской области [Текст] / Г.В. Попова // Владимирский земледелец. - 2018. № 4. - С. 37-43.

4. «Аквамикс» - концентрированное микроудобрение [Электронный ресурс] // Буйский химический завод: официальный сайт. - Режим доступа: wwwbhz. ru.

5. Сергеев, П.А. Клевер на семена [Текст] / П.А. Сергеев. - М.: Россельхозиздат, 1965. - 60 с.

6. Караванова, О.А. Изучение, выявление и создание перспективных источников клевера лугового с повышенной кормовой и семенной продуктивностью в условиях северо-западного региона России [Текст]: дисс. ... канд. с.-х. наук / Караванова Ольга Александровна. - Кострома, 2007. - 149 с.

7. Доспехов, Б.А. Методика полевого опыта [Текст] / Б.А. Доспехов. - М.: «Агропромиздат», 1985. - 351 с.

8. Методические указания по проведению полевых опытов с кормовыми культурами [Текст] / Рос. акад. с.-Х. наук; [подгот. Ю.К. Новоселов и др.]. - М.: РАСХН, 1997. - 156 с.

9. Федин, М.А. Методика государственного сортоиспытания сельскохозяйственных культур [Текст] / М.А. Федин. - М.: «Колос», 1985. - 263 с.

10. Машков, Б.М. Справочник по качеству зерна и продуктов его переработки [Текст] / Б.М. Машков, 3.И. Хазина. - М.: «Колос»,1980. - 335 с.

\section{References}

1. Mukhina, N.A. Klever krasnyj [Tekst] / N.A. Mukhina. - Kolos, 1971. - 85 s.

2. Solonichkin, V.N. Optimizacija pitanija sel'skohozjajstvennyh kul'tur na osnove primenenija nekornevyh podkormok special'nymi udobrenijami [Tekst]: posobie dlja agronomov / V.N. Solonichkin. - Buj, 2006. - 24 s.

3. Popova, G.V. Ispol'zovanie sortovogo raznoobrazija klevera lugovogo dlja sozdanija syr'evogo konvejera v uslovijah Kostromskoj oblasti [Tekst] / G.V. Popova // Vladimirskij zemledelec. - 2018. - № 4. -S. 37-43.

4. «Akvamiks» - koncentrirovannoe mikroudobrenie [Jelektronnyj resurs] // Bujskij himicheskij zavod: oficial'nyj sajt. - Rezhim dostupa: wwwbhz. ru.

5. Sergeev, P.A. Klever na semena [Tekst] / P.A. Sergeev. - M.: Rossel'hozizdat, 1965. - 60 s.

6. Karavanova, O.A. Izuchenie, vyjavlenie i sozdanie perspektivnyh istochnikov klevera lugovogo s povyshennoj kormovoj i semennoj produktivnost'ju v uslovijah severo-zapadnogo regiona Rossii [Tekst]: diss. ... kand. s.-h. nauk / Karavanova Ol'ga Aleksandrovna. - Kostroma, 2007. - 149 s. 
7. Dospekhov, B.A. Metodika polevogo opyta [Tekst] / B.A. Dospekhov. - M.: «Agropromizdat», 1985. - 351 s.

8. Metodicheskie ukazanija po provedeniju polevyh opytov s kormovymi kul'turami [Tekst] / Ros. akad. s.-h. nauk; [podgot. Yu.K. Novoselov i dr.]. - M.: RASHN, 1997. - $156 \mathrm{s.}$

9. Fedin, M.A. Metodika gosudarstvennogo sortoispytanija sel'skohozjajstvennyh kul'tur [Tekst] / M.A. Fedin. - M.: «Kolos», 1985. - $263 \mathrm{~s}$.

10. Mashkov, B.M. Spravochnik po kachestvu zerna i produktov ego pererabotki [Tekst] / B.M. Mashkov, Z.I. Khazina. - M.: «Kolos», 1980. - 335 s.

\title{
ОБЫЯВЛЕНИЕ
}

В ФГБОУ ВО Ярославская ГСХА в 2018 году издан виртуальный лабораторный практикум «ЭЛЕКТРОПРИВОД»

\author{
авторы В.В. ШМИГЕЛЬ, А.С. УГЛОВСКИЙ,
}

рекомендованный Научно-методическим советом по технологиям, средствам механизации и энергетическому оборудованию в сельском хозяйстве Федерального УМО по сельскому, лесному и рыбному хозяйству

для использования в учебном процессе при подготовке бакалавров по направлению «Агроинженерия»

В практикуме рассмотрены общие вопросы электропривода, представлены виртуальные лабораторные работы по дисциплине «Электропривод», разработанные в соответствии с программой курса для студентов бакалавриата по направлению «Агроинженерия», профиль «Электрооборудование и электротехнологии в АПК». Лабораторный практикум знакомит с методикой работы в программе Matlab/Simulink. Излагаемый материал сопровождается примерами моделирования в Simulink с использованием пакета SimPowerSistems, существенно облегчающими освоение теории электропривод.

Учебное пособие предназначено для студентов аграрных высших учебных заведений.

УДК 31.261; ББК 621.313; ISBN 978-5-98914-187-6; 204 СТР.

ПО ВОПРОСАМ ПРИОБРЕТЕНИЯ ОБРАЩАТЬСЯ ПО АДРЕСУ: 150042, г. Ярославль, Тутаевское шоссе, 58, ФГБОУ ВО Ярославская ГСХА e-mail: e.bogoslovskaya@yarcx.ru 